\title{
Usnic Acid Derivatives as Cytotoxic Agents Against Cancer Cells and the Mechanisms of Their Activity
}

\author{
Beata Guzow-Krzemińska ${ }^{1}$ Katarzyna Guzow ${ }^{2} \cdot$ Anna Herman-Antosiewicz $^{3}$ (D)
}

Published online: 16 November 2019

(C) The Author(s) 2019

\begin{abstract}
Purpose of Review This article summarises recent research on modifications of the structure or formula of usnic acid (UA), a lichen secondary metabolite, in order to obtain derivatives with higher bioavailability, potency and selectivity against cancer cells and presents the current knowledge on the mechanisms of action of such compounds.

Recent Findings Numerous approaches have been undertaken to improve bioactivity of UA concerning its use as an anticancer drug. Among them, the synthesis of UA salts or complexation with 2-hydroxypropyl- $\beta$-cyclodextrin to improve its solubility and the encapsulation using different carriers (including various nanomaterials) to stabilise UA in biological fluids and improve their penetrance to, and release in, cancer cells were applied.. Synthetic modification of the UA structure has been explored to obtain more active and cancer-specific derivatives. Recent work indicates that some modifications of the $\mathrm{C}$ or A ring of UA selectively increase its antiproliferative potential against cancer cells. Moreover, specific changes in the UA structure allow to obtain derivatives which inhibit enzymes important for the cancer cells' survival, such as mTOR, Pim, TDP1 or PARP. Some of them have been shown to enhance anticancer activity of the already approved chemotherapeutics, such as topotecan. Others, when used in an animal cancer xenograft model, were superior to UA in retardation of tumour growth and less toxic that the parent compound.

Summary UA is a promising lead compound for synthesis of anticancer drugs. Further work on its modifications, mechanisms of activity and validation in animal models is critical for development of effective therapeutics.
\end{abstract}

Keywords Lichens $\cdot$ Usnic acid $\cdot$ Cancer $\cdot$ Apoptosis $\cdot$ Encapsulation $\cdot$ Bioavailability

\section{Introduction}

Usnic acid $\left(\mathrm{C}_{18} \mathrm{H}_{16} \mathrm{O}_{7}\right)$ [2,6-diacetyl-7,9-dihydroxy-8,9bdimethyldibenzofuran-1,3(2H,9bH)-dione (UA)] is a

This article is part of the Topical Collection on Natural Products: From Chemistry to Pharmacology

Beata Guzow-Krzemińska

beata.guzow-krzeminska@ug.edu.pl

$\triangle \quad$ Anna Herman-Antosiewicz anna.herman-antosiewicz@ug.edu.pl

1 Faculty of Biology, Department of Plant Taxonomy and Nature Conservation, University of Gdańsk, Wita Stwosza 59, 80-308 Gdańsk, Poland

2 Faculty of Chemistry, Laboratory of Photobiophysics, University of Gdańsk, Wita Stwosza 63, 80-308 Gdańsk, Poland

3 Faculty of Biology, Department of Medical Biology and Genetics, University of Gdańsk, Wita Stwosza 59, 80-308 Gdańsk, Poland secondary metabolite found in lichens - especially abundant in the Alectoria, Cladonia, Evernia, Lecanora, Ramalina and Usnea genera. It constitutes approximately 4-8\% of the dry weight of thalli; however, this content may vary depending on environmental conditions [1]. It occurs in two enantiomeric forms that differ in orientation of the methyl group at the $9 \mathrm{~b}$ position: (+)-UA and (-)-UA. Both enantiomers, as well as the racemic mixture, possess a broad spectrum of biological activities. UA has antimicrobial, antiviral, antiprotozoal, antiproliferative, anti-inflammatory, anti-metastatic, anti-angiogenic, wound-healing or analgesic activities which make this compound an interesting target for the pharmaceutical industry $[2,3,4 \cdot, 5 \bullet]$. As a pure substance, UA has been used in several commercial products, such as creams, toothpaste, mouthwash, deodorants and sunscreen products [2]. It has been also reported that UA raises fat metabolism and basal metabolic rate in rodent cells [6,7], and thus, it became a constituent of supplements used for weight loss [8]. Unfortunately, it appeared to be cytotoxic not only against 
cancer cells but also against healthy cells, especially the liver cells. The use of UA in food supplements caused cases of intoxication $[9,10]$, and its negative effect on the liver cells was observed in vitro and in vivo [8]. For example, treatment of mouse primary hepatocytes with $5 \mu \mathrm{MUA}$ for $16 \mathrm{~h}$ resulted in $98 \%$ cell death [11]. Intraperitoneal injections of usnic acid suspension at a dose of $15 \mathrm{mg} / \mathrm{kg} /$ day for 15 days to male Swiss mice had caused a hepatic dysfunction as revealed by high level of serum transaminase and histological observation of necrotic areas in the livers [12].

UA is highly lipophilic, and thus highly membrane-permeable, and easily diffuses through biological membranes, resulting in the breakdown of proton gradients. Dissipation of the proton gradient across the inner mitochondrial membrane disrupts coupling between electron transport and ATP synthesis and is thought to play a major role in UA cytotoxicity [6]. Mitochondrial impairment, such as a drop in mitochondrial membrane potential, oxidative phosphorylation inhibition, ROS production, swelling, drop in ATP level and adaptive overexpression of genes associated with the electron transport chain, the Krebs cycle and lipid metabolism, have been shown to occur in the in vivo and/or in vitro models (cultured hepatocytes or cancer cells), as well as in isolated mitochondria $[6,7,11,13-17]$. Such events lead to mitochondrial pathway of apoptosis [18-22], necrosis [15] and autophagy $[14,18,23 \cdot \bullet]$. Moreover, it has been shown that proton shuttling properties of UA also affect lysosomes in the breast cancer cells (T47D, MCF-7 cell lines), but not in the normal skin fibroblasts. This leads to disruption of lysosomal acidification and consequently impaired autophagy flux [14]. Among signalling pathways, modified by UA and engaged in the processes described above were inhibition of AktmTOR-S6K/4E-BP and activation of AMPK and the MAP kinases [14, 18, 23••, 24]. It has been also demonstrated that UA disturbs calcium homeostasis in HepG2 and primary rat hepatocytes. Increase in cytosolic $\mathrm{Ca}^{2+}$ concentration upon UA treatment resulted in ER stress and subsequently activation of caspases in the HepG2 cells [19].

Anticancer activity of (-)-UA and its derivatives was first reported for the Lewis lung carcinoma and/or leukaemia cells in 1970s [25, 26]. In [26], the authors had shown that UA derivatives with increased lipophilicity were more cytotoxic against cancer cells and that the $\beta$-triketone function was necessary for maximum cytotoxicity. None of the synthetic derivatives appeared to be more potent than the parent compound in vitro [26]. In vivo, UA acetates, as well as their very close analogues with the $\beta$-triketone moiety and intact intramolecular hydrogen bonds, demonstrated moderate antitumour activity at high doses of 100-200 mg/kg [26]. Later on, both the (-)- and (+)-isomers of UA have been shown to display moderate to strong cytotoxicity against a wide panel of murine and human cancer cells in vitro [4]. For instance, $\mathrm{IC}_{50}$ of (+)-UA in the ovarian (A2780), breast (MCF-7 and SKBR-3), colon
(HT-29 and HCT116), leukaemia (HL-60 and Jurkat) and cervix (HeLa) cells was in the range of 48.5-199.2 $\mu \mathrm{M}$ (MTT, 72 h) [22].

Early work on UA structure modification proved that the disruption of the strong intramolecular hydrogen bonds of (-)UA, which is supposed to increase water solubility of the compound, failed to generate more active compounds [26]. Moreover, this study revealed importance of the $\beta$-triketone moiety for UA activity. Still, the spectrum of functional group diversity makes UA an interesting lead compound for the synthesis of derivatives with more favourable biological properties, including cytotoxic drugs for cancer therapy. Research efforts basically go in two directions: first, to improve UA bioavailability by enhancing its solubility in water or delivery into the cells; second, structure-activity-based studies to improve selectivity toward cancer cells and reduce side effects.

The purpose of this review is to summarise recent work on modifications of the UA structure in order to obtain derivatives with higher bioavailability, potency and selectivity against cancer cells and/or tumours and present the current knowledge on the mechanisms of action of such compounds.

\section{Approaches Undertaken to Enhance UA Bioavailability}

Development of novel UA formulations had been undertaken to improve its solubility and bioavailability. So far, different approaches have been proposed that include (1) application of different solvents to dissolve UA, (2) synthesis of more soluble and pharmacologically accessible salts of UA, (3) encapsulation of UA and (4) use of nanomaterials as potential carriers of UA.

Kristmundsdottir et al. tested different pharmaceutical solubilising agents to increase solubility of (+)-UA and evaluated their effects on UA cytotoxicity against the human erythro-leukaemia K-562 cell line. They concluded that complexation with 2-hydroxypropyl- $\beta$-cyclodextrin (HP- $\beta$-CD), which was not toxic and improved the UA solubility that allowed to reach a concentration that gave a significant antiproliferative activity against the K-562 cells, is very promising for further therapeutic applications [27]. Complexes of UA with $\beta$-cyclodextrin $(\beta-\mathrm{CD})$ and HP- $\beta-\mathrm{CD}$ were used by Nicolić et al. in antibacterial and antifungal activity tests [28]. Moreover, Lira et al. used $\beta$-CD to improve (+)-UA solubility and the inclusion complex (UA: $\beta$-CD) was encapsulated into liposomes which were further tested for antimycobacterial activity [29].

Recently, Yang et al. tested bioavailability and anticancer activity of potassium salt of (+)-usnic acid (KU) in an in vitro and in vivo experimental model of colorectal cancer [30••]. They concluded that potassium usnate has promising properties, as the amounts of KU in the tumours, liver and plasma of 
CT26 syngeneic tumour xenograft-bearing mice were higher than those of UA after oral administration, thus proving a better salt bioavailability than that of UA itself. Moreover, KU had potent anticancer effects on the human and mouse colorectal cancer cell lines (HCT116, DLD1, SW480, HT29, SW620, Caco2, COLO320 and CT26), with a significantly lower $\mathrm{IC}_{50}$ value than $\mathrm{UA}$, in most cases (the exceptions were the SW480 and CT26 cells). Moreover, KU did not cause additional hepatotoxicity, as the level of aspartate aminotransferase was significantly lower in the mice treated with 20 $\mathrm{mg} / \mathrm{kg} \mathrm{KU}$ than in the control groups.

Encapsulation into nanocapsules should protect the drug from degradation in biological fluids and improve its penetration into cells. Ribeiro-Costa et al. used biodegradable copolymers of lactic and glycolic acid (PLGA)-microspheres loaded with UA and evaluated their cytotoxicity towards larynx epidermoid carcinoma HEp-2 cells using the MTT method. They found no significant difference between free and encapsulated UA, with $\mathrm{IC}_{50}$ values of 12.6 and $14.4 \mu \mathrm{g} / \mathrm{ml}$, respectively [31]. Similarly, Santos et al. also used UA-loaded PLGA nanocapsules to evaluate their cytotoxicity against human lung carcinoma NCI-H 292 cells and determined $\mathrm{IC}_{50}$ values to be 10 and $13.8 \mu \mathrm{g} / \mathrm{ml}$ for free and encapsulated UA, respectively [32].

Moreover, both Ribeiro-Costa et al. and da Silva Santos et al. tested the anticancer activity of PLGA-encapsulated UA in mice against the Sarcoma-180 tumour $(15 \mathrm{mg} / \mathrm{kg}$ body weight/day, administered for 7 days) and both found that the application of UA-loaded PLGA microspheres inhibited tumour growth more effectively than free UA (63-69.7\% vs $42-43.3 \%$ of tumour inhibition) $[12,31]$. The increase in tumour inhibition activity by $21 \%$ [31] or $26.4 \%$ [12] in comparison with free UA indicated that encapsulation is a promising approach in chemotherapy, especially that hepatotoxicity, observed as vacuolisation of hepatocytes and lymphocytic infiltration in portal spaces, was reduced in animals treated with UA-loaded PLGA nanocapsules [12]. Other types of encapsulation were used for antibacterial tests of UA, e.g. carboxylated poly(L-lactide) (cPLLA) microparticles [33], liposomes [29, 34], hybrid core/shell iron oxide magnetic nanoparticles [35], manganese/iron oxide magnetic nanoparticles [36] and magnetic polylactic-co-glycolic acid-polyvinyl alcohol (PLGA-PVA) microsphere thin films [37].

UA-nanocrystal suspension (NCS) was developed by a wet milling method to improve UA bioavailability. Its uptake in the human colon cancer Caco-2 cells, as well as its pharmacokinetics in rats were tested [38]. The authors had shown that application of UA-NCS had increased the cellular uptake and absorption rates by about 3 times. Moreover, in pharmacokinetic experiments where UA-NCS was administered orally, a higher concentration of UA was observed in the rat plasma when compared with the control group treated with UA-S, and thus, UA bioavailability was improved by using an UAnanocrystal suspension [38]. A similar innovation, where nanoparticles obtained by a nanoprecipitation method displayed good water solubility and cell permeability and thus improved UA bioavailability in rats by $505 \%$, was patented by Qu et al. (2015; patent no. CN104398477), as reported by Luzina and Salakhutdinov [39•].

Recently, Garg et al. had developed and tested heparinmodified gellan gum (HAG) nanoparticles (NPs) loaded with $(+)$-UA [ $40 \bullet \cdot$. Gellan gum is a linear anionic polysaccharide consisting of tetrasaccharide units $(1,3-\beta$-D-glucose, $1,4-\beta$-Dglucuronic acid, $1,4-\beta$-D-glucose, $1,4-\alpha$-L-rhamnose) with one carboxyl side group, and it is used in the biomedical and food industries. They found that UA-loaded HAG NPs exhibited cytotoxic potential against the A549 human lung cancer cells. Moreover, in the in vivo biodistribution tests using an albino rat model, the amount of UA was measured in different organs after $2 \mathrm{~h}$ of administration. The authors detected free UA at the following concentrations: $7.09 \%$ in the heart, $2.7 \%$ in the lung, $2.06 \%$ in the stomach, $7.5 \%$ in the kidney, $9.2 \%$ in the liver, $8.7 \%$ in the intestine and $4.5 \%$ in the spleen. However, in the case of UA-loaded HAG NPs, a higher percentage was acquired only in the lung, i.e. $7.7 \%$, while in the other organs, it was lower, i.e. $4.1 \%$ in the heart, $1.8 \%$ in the stomach, $2.9 \%$ in the kidney, $2.21 \%$ in the liver, $2.2 \%$ in the intestine and $1.85 \%$ in the spleen $[40 \cdot \bullet$.

Moreover, Garg et al. had used a similar approach and the same model, i.e. the A549 human lung cancer cells, to test the cytotoxicity of (+)-UA enclosed in heparin-modified cellulose acetate phthalate (HEC) nanoparticles (NPs) [41]. Cellulose acetate phthalate (CAP), a cellulose polymer which consists of the phthalyl $\left(\mathrm{C}_{8} \mathrm{H}_{5} \mathrm{O}_{3}\right)$ and acetyl $\left(\mathrm{C}_{2} \mathrm{H}_{3} \mathrm{O}\right)$ groups, is used for enteric film coating of tablets and capsules and provides a sustained and controlled release of a given drug. The authors found that HEC NPs have a slower in vitro drug release ( $96.21 \%$ in $32 \mathrm{~h}$ ) in comparison with CAP NPs $(97.36 \%$ in $8 \mathrm{~h}$ ). Moreover, the haemolytic toxicity was highest in the case of UA (28.31\%), while it was lower in UA-loaded HEC NPs (4.19\%) and UA-loaded CAP NPs (8.09\%). Additionally, UA-loaded HEC NPs demonstrated a potent cytotoxic activity against lung cancer cells and thus revealed promising properties for further development as an anticancer drug delivery system [41].

A different approach was proposed by Mukerjee et al. who evaluated the anticancer and antioxidant properties of cinnamon oil and (+)-usnic acid-blended nanoemulsion (CUN) against chemically induced skin carcinogenesis in mice [42]. They found that CUN had significantly reduced the number of tumours in mice after 16 weeks (from 39.36 in positive control, to 14.35 in post-CUN, and 7 in peri-post-CUN-treated mice). Additionally, histopathological investigation indicated 


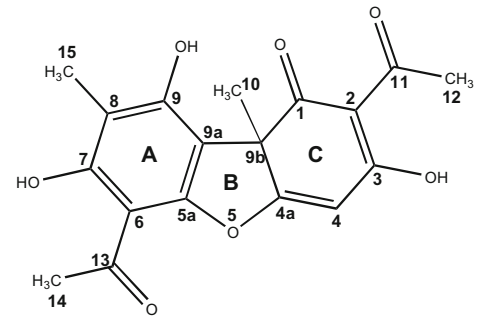

A
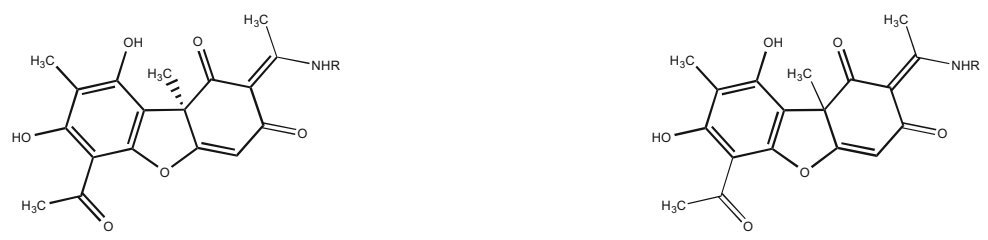

B: $\mathrm{R}=-\left(\mathrm{CH}_{2}\right)_{8}-\mathrm{NH}_{2}, 2 \mathrm{HCl}$
C: $\mathrm{R}=-\left(\mathrm{CH}_{2}\right)_{3}-\mathrm{NH}-\left(\mathrm{CH}_{2}\right)_{4}-\mathrm{NH}_{2}, 3 \mathrm{HCl}$<smiles></smiles>
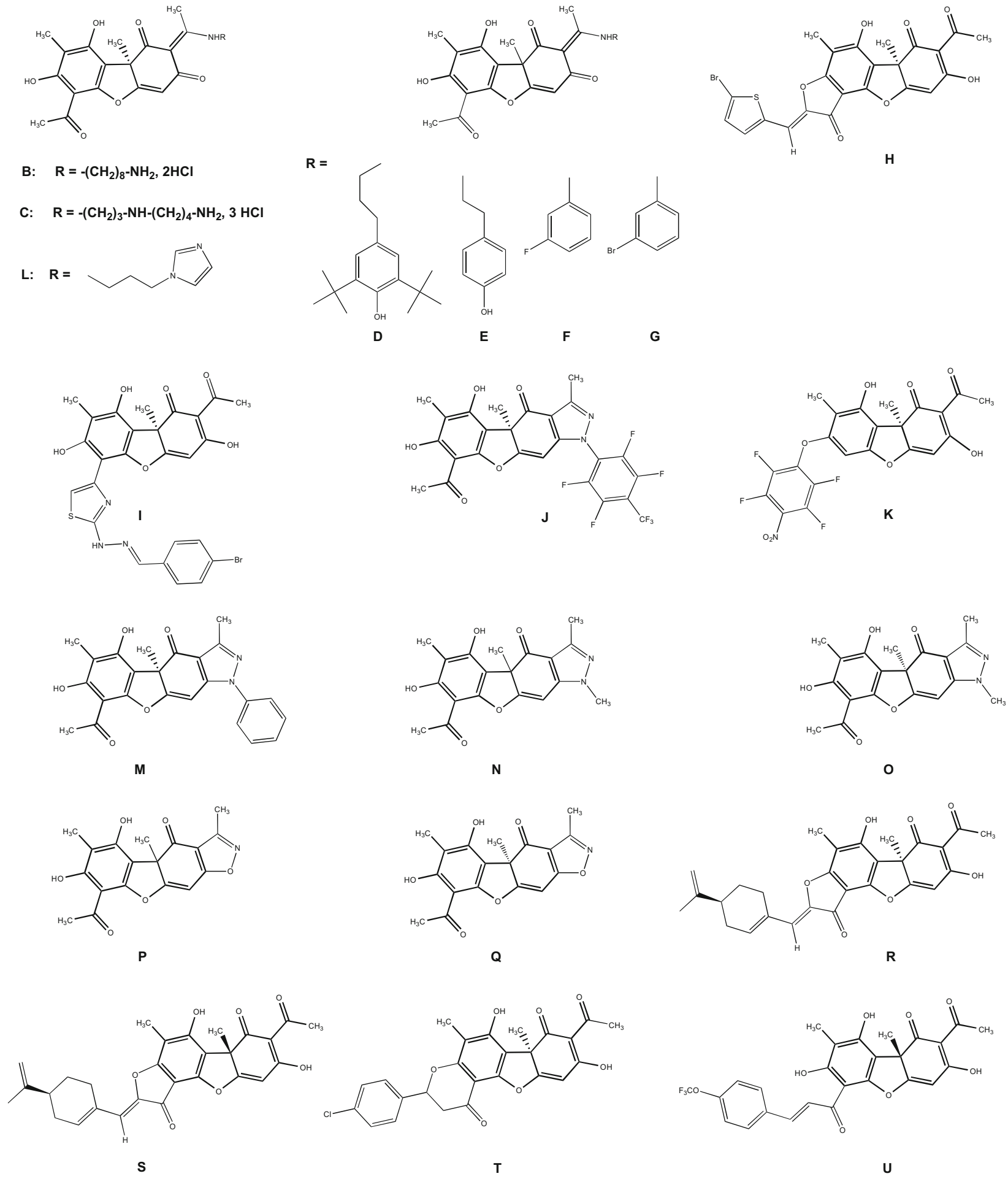
Fig. 1 Structures of usnic acid and its biologically active derivatives. (A) Usnic acid (2,6-diacetyl-7,9-dihydroxy-8,9b-dimethyldibenzofuran1,3(2H,9bH)-dione). (B) 6-Acetyl-2-[1-(8-aminooctylamino)ethylidene]7,9-dihydroxy-8,9b-dimethyldibenzofuran-1,3(2H,9bH)-dione (hydrochloride salt) [45]. (C) 6-Acetyl-2-\{1-[3-(4-aminobutylamino) propylamino] ethylidene $\}$-7,9-dihydroxy-8,9b-dimethyldibenzofuran1,3(2H,9bH)-dione (hydrochloride salt) [45]. (D) (E)-6-Acetyl-2-[1-(3,5-ditert-butyl-4-hydroxyphenpropylamino)ethylidene]-7,9-dihydroxy-8,9bdimethyldibenzo[ $b, d]$ furan-1,3(2H,9bH)-dione [46]. (E) (E)-6-Acetyl-7,9dihydroxy-2-[1-(4-hydroxyphenethylamino)ethylidene]-8,9bdimethyldibenzo[b,d]furan-1,3(2H,9bH)-dione [46]. (F) (E)-6-Acetyl-2-[1(4-fluorophenylamino)ethylidene]-7,9-dihydroxy-8,9bdimethyldibenzo[b,d]furan-1,3(2H,9bH)-dione [46]. (G) (E)-6-Acetyl-2-[1(4-bromophenylamino)ethylidene]-7,9-dihydroxy-8,9bdimethyldibenzo[b,d]furan-1,3(2H,9bH)-dione [46]. (H) (4Z,10R)-12Acetyl-8,13-dihydroxy-7,10-dimethyl-4-(5-bromothiophen-2ylmethylidene)-5,16-dioxatetracyclo[7.7.0.02,6.010,15]hexadeca1(9),2(6),7,12,14-pentaene-3,11-dione [47]. (I) (R,E)-2-Acetyl-6-(2-(2-(4bromobenzylidene)hydrazinyl)thiazol-4-yl)-3,7,9-trihydroxy-8,9bdimethyldibenzo[b,d]furan-1(9bH)-one [48・•]. (J) (R)-8-Acetyl-5,7dihydroxy-3,4a,6-trimethyl-1-[2',3',5',6'-tetrafluoro-4'-(trifluoromethyl) phenyl]-1H-benzofuro[3,2-f]indazol-4(4a $H$ )-one [49]. (K) 2,6-Diacetyl-3,9dihydroxy-7-(2',3',5',6'-tetrafluoro-4'-nitrophenoxy)-8,9b-dimethyl-9b $H$ dibenzofuran-1-one [49]. (L) (R,E)-6-Acetyl-2-[1-(3-(1H-imidazol-1yl)propylamino)ethylidene]-7,9-dihydroxy-8,9b-dimethyldibenzofuran1,3(2H,9bH)-dione [50]. (M) (R)-8-Acetyl-5,7-dihydroxy-3,4a,6-trimethyl1-phenyl-1H-benzofuro[3,2-f]indazol-4(4aH)-one [50]. (N) 8-Acetyl-5,7dihydroxy-1,3,4a,6-tetramethyl-1,4a-dihydro-4H-benzofuro[3,2-f]indazol4-one [51]. (O) (R)-8-Acetyl-5,7-dihydroxy-1,3,4a,6-tetramethyl-1,4adihydro-4H-benzofuro[3,2-f]indazol-4-one [51]. (P) 8-Acetyl-5,7dihydroxy-3,4a,6-trimethylbenzo[2,3]benzofuro[5,6-d]isoxazol-4(4a $H)$-one [51]. (Q) (R)-8-Acetyl-5,7-dihydroxy-3,4a,6-trimethylbenzo[2,3]benzofuro [5,6-d]isoxazol-4(4aH)-one [51]. (R) (4Z,10R)-12-Acetyl-8,13-dihydroxy7,10-dimethyl-4-\{[(4S)-4-(prop-1-en-2-yl)cyclohex-1-en-1yl]methylidene $\}$-5,16-dioxatetracyclo[7.7.0.02,6.010,15]hexadeca1,6,8,12,14-pentaene-3,11-dione [52]. (S) (4Z,10S)-12-Acetyl-8,13dihydroxy-7,10-dimethyl-4- $\{[(4 \mathrm{~S})-4$-(prop-1-en-2-yl)cyclohex-1-en-1yl]methylidene \}-5,16-dioxatetracyclo[7.7.0.02,6.010,15]hexadeca1,6,8,12,14-pentaene-3,11-dione [52]. (T) (6bR)-8-Acetyl-3-(4chlorophenyl)-6,9-dihydroxy-5,6b-dimethyl-2,3-dihydro- $1 \mathrm{H}-$ benzofuro[2,3-f]chromene-1,7(6bH)-dione [53]. (U) (S,E)-2-Acetyl-3,7,9trihydroxy-8,9b-dimethyl-6-\{3-[4-(trifluoromethoxy)phenyl] acryloyl $\}$ dibenzo[ $[b, d]$ furan-1 $(9 \mathrm{~b} H)$-one $[23 \cdot \bullet]$

less damage to the skin architecture, reduced hyperkeratosis and epidermal hyperplasia in the case of post-CUN mice, while in peri-post-CUN mice, the number and the size of keratinised pearls, acanthosis and tumour were reduced [42]. Thus, CUN is a promising candidate for further clinical studies on formulation that reduces skin carcinogenesis.

Garg et al. introduced a carbon nanomaterial (nanodiamond, ND) due to its low toxicity, high chemical stability, high affinity for biomolecules and ease of surface functionalisation [43]. They developed (+)-UA bound with the surface modified nanodiamond (ND) via adipic acid dihydrazine (ADH) and tested its cytotoxicity on the human breast cancer MCF-7 and human hepatoma HepG2 cell lines. The authors claimed that the optimised ND-drug conjugates have greater inhibitory effect; however, the figures presenting percentage of growth inhibition showed a stronger growth inhibitory effects of UA than NDADH-UA [43].

\section{Synthesis/Semisynthesis of UA Derivatives with Improved Antiproliferative Activity and Pharmacological and Toxicity Profiles}

The most numerous group of UA derivatives includes enamine-type compounds. They are obtained by the reaction of the carbonyl group of UA with primary amines. This changes the "triketone" moiety, with loss of the acidic proton, and leads to reduction of UA toxicity and membrane uncoupling activity. Biological properties and solubility of UA enamine derivatives are improved in comparison with UA. These derivatives have been first isolated from Usnea longissima using ${ }^{1} \mathrm{H}$ NMR-guided fractionation and were shown to be cytotoxic towards the HepG2 cells [44]. Bazin et al. synthesised nine (+)-UA derivatives conjugated to natural polyamines (putrescine, spermidine and spermine), nonylamine, 1,8diaminooctane, aminobutanol or amino acids (L-isoleucine, Lleucine ester and L-phenylalanine ester). Their impact on cell survival was investigated by MTT ( 48 or $72 \mathrm{~h}$ ), using a panel of murine and human cancer cell lines [45]. The authors found that natural polyamine derivatives were more active towards the murine lymphocytic leukaemia $\mathrm{L} 1210$ cells $\left(\mathrm{IC}_{50}=8.4\right.$ $15.3 \mu \mathrm{M})$ than $(+)-\mathrm{UA}\left(\mathrm{IC}_{50}=26.4 \mu \mathrm{M}\right)$ or $(-)$-UA $\left(\mathrm{IC}_{50}=\right.$ $17.4 \mu \mathrm{M})$, and it was not a result of an additive cytotoxicity of the two components of conjugates. Aminobutanol and amino acid derivatives were less active, while a diaminooctane derivative 4 (Fig. 1, compound B) was the most active towards the L1210 cells $\left(\mathrm{IC}_{50}=2.7 \mu \mathrm{M}\right)$, where it induced apoptosis. This compound had a 3- to 18 -fold higher activity than the parent (+)-UA towards cancer cells and was tested on the murine Lewis lung carcinoma 3LL, human chronic myelogenous leukaemia K-562, human glioblastoma U251, human breast adenocarcinoma MCF-7, human prostate carcinoma DU-145 and non-cancerous Chinese Hamster Ovary $\mathrm{CHO}$ (and polyaminetransport-deficient CHO-MG) cells (Table 1). Moreover, higher activity of derivative 4 (Fig. 1, compound B), when compared with its spermidine analogue 2 (Fig. 1, compound C), indicated the importance of the long lipophilic alkyl chain which may facilitate cell membrane crossing and the importance of a primary amino group at the end of the alkyl chain (the nonylamine derivative was inactive). The authors of this study hypothesised that conjugation of UA with amines would improve efficacy of the tested compounds, as they become substrates to polyamine transport system (PTS) which is highly active in rapidly dividing cancer cells. However, their work had shown that activity of the conjugates was independent of PTS - none of the conjugates with natural polyamines exhibited preferential activity in a cell line with high PTS activity [45].

In another study, ten derivatives of (+)-UA were synthesised with ethylene diamine or a series of aromatic amines, with subsequent treatment with hydroxylamine hydrochloride. As a result, UA ketamines and their oxime analogues were obtained and evaluated by MTT 
assay with the human glioblastoma-astrocytoma cells U87MG. The ketamine derivatives had a significant cytotoxicity, and a novel $\mathrm{N}$-heterocyclic derivative $(1,4-$ diazepine, 2) was more active than (+)-UA itself $\left(\mathrm{CC}_{50}\right.$ $=33$ vs $47 \mu \mathrm{M}$ ) or temozolomide, a drug approved for GBM treatment [54]. However, the mechanism underlying activity of the tested derivatives has not been studied in this work.

The Olga Lavrik group had synthesised a series of (+) and $(-)$-UA enamines and shown that some of them (those with a bulky aromatic substituent at the $\mathrm{C}$ ring, such as 3,5-di-tertbutyl-4-hydroxyphenyl, 4-hydroxyphenyl or halogenated phenyl derivatives; Fig. 1, compounds D-G) potently inhibited the tyrosyl-DNA phosphodiesterase I (TDP1) [46]. This enzyme is engaged in processing $3^{\prime}$-lesions in DNA, which are generated, among others, during inhibition of topoisomerase I (Top1), when Top1-DNA covalent complexes are formed. These lesions' accumulation, due to lack of TDP1, leads to single- and double-strand DNA breaks and eventually to cell death. Thus, it was supposed that inhibition of TDP1 may enhance therapeutic effect of Top1 inhibitors, especially in tumours with high level of TDP1. Indeed, some UA enamines have been shown to enhance cytotoxicity of camptothecin by 1 order of magnitude. The most active was derivative 8 (Fig. 1, compound $\mathrm{D}$ ), which had increased sensitivity of the MCF-7 cells to camptothecin by 10 -fold $\left(\mathrm{CC}_{50}\right.$ $=192 \mu \mathrm{M}$ without conjugate, and $18 \mu \mathrm{M}$ with an UA derivative), at a safe for these cells concentration of $0.5 \mu \mathrm{M}\left(\mathrm{CC}_{50}\right.$ $>50 \mu \mathrm{M}$ ). Importantly, this was not a cell line-specific effect, as this compound also sensitised the A-549 lung cancer cells to the drug (3.5-fold enhancement) (Table 1). Interestingly, the authors did not observe a significant difference in activity of the stereoisomers of UA derivatives [46].

As the presence of native substituents in the $\mathrm{C}$ ring is important for penetration of UA derivatives through biological membranes [39•], in further research, 29 UA derivatives were synthesised with an intact $\mathrm{C}$ ring, but with aryl or heteroarylidenfuranone moieties at the A ring [47]. Among them, 5-bromothiophen-2-yl UA derivative 6× (Fig. 1, compound $\mathrm{H}$ ) had revealed promising activities. It strongly inhibited TDP1 $\left(\mathrm{IC}_{50}=63 \mathrm{nM}\right)$, being at the same time moderately cytotoxic against the A-549 and HEK-293 cells $\left(\mathrm{CC}_{50}\right.$ $=8.7$ and $15.7 \mu \mathrm{M}$, respectively). At a non-toxic concentration, it sensitised these cells to a bioavailable derivative of camptothecin, topotecan (approx. 2-fold increase in cytotoxicity of the drug when administered with the compound $6 \mathrm{x}$ ) (Table 1). Interestingly, the authors did not observe a correlation between the UA derivatives' activity against a pure enzyme and their cytotoxicity and ability to enhance the topotecan effect, which was explained by possible existence of substrates other than TDP1 in the cancer cells [47].

Later, the same team had synthesised a novel class of thiazole, aminothiazole and hydrazinothiazole UA derivatives.
Among them, four hydrazinothiazole derivatives, 20c, 20d, $20 \mathrm{~h}$ and 20i, strongly inhibited the TDP1 enzyme activity in the nanomolar range $\left(\mathrm{IC}_{50}=26-86 \mathrm{nM}\right)$. Furthermore, the most effective TDP1 inhibitor, compound 20d (Fig. 1, compound I) with a bromophenyl substituent, was non-toxic $\left(\mathrm{LD}_{50}>5000 \mathrm{mg} / \mathrm{kg}\right)$ and significantly increased the effect of topotecan against the Lewis lung carcinoma cells, both in in vitro and in vivo mice model (Table 1) [48••].

Numerous (+)-UA derivatives were synthesised and their influence on autopoly (ADP-ribosyl)ation catalysed by purified PARP1 and DNA synthesis catalysed by DNA polymerase $\beta$ were tested by the Lavrik team [49]. Inhibition of enzymes engaged in the DNA repair can be an efficient way to potentiate anticancer therapies which target DNA integrity. The pyrazole derivatives of UA (18-25), especially compound 24 (Fig. 1, compound J), and their hydrazones (2630) were found to be more selective inhibitors of PARP1, as the residual activity of polymerase $\beta$ exceeded that of PARP1 by 2-5-fold, with the exception of compound 31 exhibiting the same effect on both enzymes. Moreover, the enamine derivative of UA (11) also selectively inhibited the activity of PARP1 (17\% residual activity, 7-fold in comparison with DNA polymerase $\beta$ ). Derivatives containing polyfluoroaromatic substituents at the A ring $(35,37$ and 39$)$ appeared to moderately inhibit PARP (residual activity was 21-39\%) and derivative 39 (Fig. 1, compound K) also inhibited polymerase $\beta$ (residual activity was $43 \%$ ). Compounds 24 and 39 (Fig. 1, compounds J and K, respectively) were moderately cytotoxic towards the MCF-7 $\left(\mathrm{IC}_{50}=75\right.$ and $79 \mu \mathrm{M}$, respectively) and LMTK (IC50 = 17 and $35 \mu \mathrm{M}$, respectively) cells. The data presented indicated that the UA derivatives interact with PARP in a nonspecific way, as their inhibitory activities depended only on the presence of aromatic substituents and not on their nature or position [49].

Mallavadhani et al. had synthesised 21 (+)-UA derivatives belonging to enamines or pyrazoles and tested them against the HeLa (cervical), MDA MB 231 (breast), A549 (lung) and MIA PaCa-2 (pancreatic cancer) cells (SRB, 48 h) [50]. All derivatives revealed an enhanced antiproliferative activity in comparison with the parent compound, except for $3 \mathrm{~b}$ and $4 \mathrm{~b}$ in the case of A549, and 3b and $4 \mathrm{c}$ in the case of MIA PaCa-2 cells. The mechanisms of activity of the most potent $2 \mathrm{e}$ derivative (Fig. 1, compound L; an enamine derivative with $\mathrm{IC}_{50}=$ 3.9-6 $\mu \mathrm{M}$, depending on the cell line) and 4 a derivative (Fig. 1 , compound $\mathrm{M}$; a pyrazole derivative with $\mathrm{IC}_{50}=5.9-7.4$ $\mu \mathrm{M})$ were examined in HeLa cells. They induced the G2/M cell cycle arrest and drop in the level of polymerised tubulin, when used at $10 \mu \mathrm{M}$ concentration for $24 \mathrm{~h}$ (Table 1) [50].

Recently, isoxazole and pyrazole derivatives of (+)-UA and racemic UA were synthesised [51]. The authors hypothesised that replacement of the 1,3-dicarbonyl functionality by bioisosteric heterocycles would lock the accessible 
Table 1 Examples of UA derivatives with high potency against cancer cells and investigated mechanisms of their activity

Compound Model/activity Rechanism

4 (Fig. 1 B) L1210, 3LL, DU145, MCF-7, K-562 and U251

2 (Fig. 1 C) cancer cells $\left(\mathrm{IC}_{50}=2.7-14.1 \mu \mathrm{M}\right.$; for comparison $\left.\mathrm{UA} \mathrm{IC}_{50}=17.4-51.7 \mu \mathrm{M}\right)$, toxic to normal cells $(\mathrm{CHO})$

Quite selective for cancer cells $\left(\mathrm{IC}_{50}=8.4-12.5 \mu \mathrm{M}\right.$, while for non-cancerous cells $29 \mu \mathrm{M}$ )

3 (Fig. 1 F)

6 (Fig. $1 \mathrm{G}$ )

8 (Fig. 1 D)

9 (Fig. 1 E)

6x (Fig. $1 \mathrm{H})$

20d (Fig. 1 I)

Moderately or no toxic to MCF-7 $\left(\mathrm{IC}_{50}=18->50 \mu \mathrm{M}\right)$

and A-549 cells $\left(\mathrm{IC}_{50}=70-100 \mu \mathrm{M}\right)$ but

potentiate cytotoxicity of camptothecin

Cytotoxic to cancer A-549 cells $($ IC50 $=8.7 \mu \mathrm{M})$, less to non-cancerous HEK-293 $\left(\mathrm{IC}_{50}=15.7 \mu \mathrm{M}\right)$, potentiates cytotoxicity of topotecan

Cytotoxic to MCF-7 and LLTC cells $\left(\mathrm{IC}_{50}=1.7 \mu \mathrm{M}\right)$, synergistic activity with topotecan. Non-toxic to mice; at dose $100 \mathrm{mg} / \mathrm{kg}$ (oral administration) potentiates antiproliferative and anti-metastatic activity of topotecan in mice with lung carcinoma Lewis

24 (Fig. $1 \mathrm{~J}$ )

39 (Fig. $1 \mathrm{~K}$ )

2e (Fig. $1 \mathrm{~L}$ )

4a (Fig. $1 \mathrm{M}$ )

2b (Fig. 1 Q)

2a (Fig. 1 P)

3b (Fig. $1 \mathrm{O}$ )

3a (Fig. $1 \mathrm{~N})$

$15 \mathrm{~g}$ (Fig. $1 \mathrm{R})$

16 g (Fig. $1 \mathrm{~S}$ )

6 g (Fig. 1 T)

Weakly to moderately toxic to MCF-7 $\left(\mathrm{IC}_{50}=70-75 \mu \mathrm{M}\right)$ and LMTK cells $\left(\mathrm{IC}_{50}=17-35 \mu \mathrm{M}\right)$

Cytotoxic to HeLa, MDA MB 231, A-549, MiaPaca $\left(\mathrm{IC}_{50}=3.9-5.99 \mu \mathrm{M}\right.$ and 5.9-7.4 $\mu \mathrm{M}$, respectively; for comparison (+)-UA IC $\mathrm{IC}_{50}=61.5-88.2 \mu \mathrm{M}$ )

Cytotoxic to HeLa, MCF-7, PC-3 cancer cells $\left(\mathrm{IC}_{50}=1-3.4 \mu \mathrm{M}\right.$ after $24 \mathrm{~h}$ ), less toxic to HDFa normal fibroblasts $\left(\mathrm{IC}_{50}=9.2 \mu \mathrm{M}\right)$

Active only toward HeLa cells $\left(\mathrm{IC}_{50}=2.7 \mu \mathrm{M}\right)$

Weakly cytotoxic to MCF-7, T98G, SW 837 and HEK 293 $\left(\mathrm{CC}_{50}>60 \mu \mathrm{M}\right)$

Cytotoxic to HL-60 and K562 leukaemia cells $\left(\mathrm{IC}_{50}=2.6-2.7 \mu \mathrm{M}\right.$, for comparison $\left.\mathrm{UA} \mathrm{IC}_{50}=10-10.5 \mu \mathrm{M}\right)$

52 (Fig. $1 \mathrm{U}$ )

Cytotoxic to MDA MB 231, MDA MB 468, MCF-7, T47D, SKBR3, BT474 breast cancer cells $\left(\mathrm{IC}_{50}=0.28-0.35 \mu \mathrm{M}\right.$, for comparison $\mathrm{UA} \mathrm{IC}_{50}=11-16 \mu \mathrm{M}$ ), non-cancerous MCF10A cells more resistant. Inhibits growth of tumours in MCF-7 or MDA MB 231-xenografted mice (10 mg/kg, 3× week, ip administration) by $62-65 \%$ compared with controls
Induce apoptosis (caspase 3 activation). Activity independent on polyamine transport system

Inhibit TDP1 with $\mathrm{IC}_{50}=0.16-1.39 \mu \mathrm{M}$

Inhibits TDP1 with $\mathrm{IC}_{50}=63 \mathrm{nM}$

Inhibits TDP1 with $\mathrm{IC}_{50}=26 \mathrm{nM}$

Inhibit PARP1 (PARP1 residual activity of $17 \%$ and $21 \%$, respectively)

Arrest cell cycle at $\mathrm{G} 2 / \mathrm{M}$, inhibit microtubule polymerisation

G0/G1 cell cycle arrest, induction of apoptosis, induction of massive cytoplasmic vacuolisation which is associated with dynamin-mediated endocytosis

Inhibit TDP1 with $\mathrm{IC}_{50}=0.41$ and $0.33 \mu \mathrm{M}$, respectively

Induction of apoptosis (with cleavage of pro-caspase 9 and 3, and PARP), drop in MCl-1, p-eIF4E, p-4E-BP, p-BAD, inhibition of Pim Ser/Thr kinases

Inhibits mTOR with drop in p-S6K, p-4E-BP, p-Akt and induction of autophagy
An interesting approach was undertaken by Dyrkheeva et al. who combined UA with moieties known for their biological activities [52]. They used terpenophenols to modify the (+)- and (-)-UA. They introduced monoterpenic substituents (acylic, mono- or bicyclic) into a furanone ring annealed to the A ring of UA (derivative 13). Derivatives of both (+)and (-)-UA with linear substituents (15a-b and 16a-b) and a cyclohexene modification (15 g and $16 \mathrm{~g}$, Fig. 1, compounds $\mathrm{R}$ and $\mathrm{S}$, respectively) revealed inhibitory activity towards TDP1 at low concentrations $\left(\mathrm{IC}_{50}=0.33-2.7 \mu \mathrm{M}\right)$. The authors suggested that planarity and flexibility of the fragment linked to the furanone ring via a double bond,are crucial for TDP1 binding. Neither the terpenic substituent nor UA enantiomeric structure had a significant effect on inhibitory properties of the tested compounds. All derivatives were less toxic

(Table 1) [51]. 
towards different cancer cells than UA. The most promising were compounds $15 \mathrm{~g}$ (Fig. 1, compound R) and $16 \mathrm{~g}$ (Fig. 1, compound $\mathrm{S})$, which exhibited a weak cytotoxicity $\left(\mathrm{CC}_{50}>\right.$ $60 \mu \mathrm{M}$ ) against MCF-7 (breast), T98G (brain), SW837 (rectum) cancer cells and HEK293 embryonic kidney cells and strongly inhibited TDP1 $\left(\mathrm{IC}_{50}=0.41\right.$ and $0.33 \mu \mathrm{M}$, respectively) (Table 1) [52].

The C-6 acetyl and C-7 hydroxyl groups of UA A-ring were modified by Wang et al. who synthesised seven (+)UA derivatives with a flavanone moiety, and which were tested in the leukaemia cells (HL-60 and K562) [53]. Introduction of the flavanone moieties, especially the halogenated ones, resulted in about 4-fold improvement in the anticancer activity when compared with the (+)-UA ( $\mathrm{IC}_{50}$ of UA was approx. 10 $\mu \mathrm{M})$. After $18 \mathrm{~h}$ of treatment, the 4-chloro-substituted derivative $6 \mathrm{~g}$ (Fig. 1, compound $\mathrm{T})\left(\mathrm{IC}_{50}=2.7 \mu \mathrm{M}\right)$ induced apoptosis of leukaemia cells with involvement of the mitochondrial pathway (Mcl-1 and p-BAD downregulation). It also reduced phosphorylation of eIF4F. Moreover, it reduced phosphorylation of 4E-BP1 and BAD and thus the cap-dependent translation and proapoptotic function of $\mathrm{BAD}$, respectively, which was mediated by inhibition of Pim Ser/Thr kinases (supported by an in vitro kinase assay and molecular docking analysis) [53]. Interestingly, the inhibitory activity of compound 6 g (Fig. 1, compound T) against Pim kinases was almost the same as that of (+)-UA, but the cytotoxic potential of this derivative was higher than that of the parent compound, which indicates that it has other targets in the cancer cells (Table 1).

Based on an observation that (+)-UA induced autophagy in different breast cancer cells, Ebrahim et al. hypothesised that it inhibits the mTOR kinase activity [23••]. Molecular docking analysis supported this hypothesis. The authors rationally designed a series of benzylidene analogues of (+)-UA (at the C-6 acetyl group) that would fit into an mTOR kinase pocket better than UA, and indeed, most of them had revealed a higher than the parent compound cytotoxic activity towards MCF-7 and MDA MB 231 cell lines. At nanomolar concentrations, compound 52 (Fig. 1, compound $\mathrm{U}$ ) appeared to be an especially potent inhibitor of mTOR (assessed by induction of autophagy and reduction in p-S6K, p-4E-BP and p-Akt levels), cell survival ( $\mathrm{IC}_{50}$ approx. $0.3 \mu \mathrm{M}$ when compared with UA $\mathrm{IC}_{50}=13-16 \mu \mathrm{M}$ ), clonogenic potential, cell migration and invasiveness. Importantly, this derivative was quite safe for nontumourigenic MCF-10A mammary epithelial cells (up to approx. 6-fold of its $\mathrm{IC}_{50}$ against malignant cell lines). It also revealed a promising antitumour activity in the mice xenograft models, reducing tumour growth by $62-65 \%$ when compared with control, vehicle-treated animals (Table 1) $[23 \bullet \bullet]$.

Benzylidene analogues were also obtained by Nguyen et al. by direct coupling between UA and a variety of aromatic aldehydes [55]. Their cytotoxicity was tested against the
K562 (chronic myelogenous leukaemia) and HEK293 (human embryonic kidney) cell lines. There, especially compound $2 \mathrm{e}$ had revealed a promising activity, as it decreased the viability of cancer cells, with $\mathrm{IC}_{50}=4.5 \mu \mathrm{M}$ after 24-h treatment and was inactive towards the non-cancerous HEK293 cells $\left(\mathrm{IC}_{50}>100 \mu \mathrm{M}\right)$. Unfortunately, the mechanism of its activity has not been explored in that study [55].

\section{Conclusions}

Usnic acid, both the (+) and (-) enantiomers, as well as their racemic mixture, display numerous biological activities, including cytotoxic activities against cancer cells. As their physicochemical features and hepatotoxicity restrict their use in the clinics, there is ongoing work on modifications of the UA structure or formulations in order to obtain derivatives with better than UA pharmacological properties, anticancer activities and higher safety to healthy cells. The presented results are promising; however, more work has to be performed before their use in treatment of human cancers. Among different approaches, application of UA salts or nanoencapsulated UA, which proved to improve bioavailability, as well as safety of UA in animal models, are very promising. However, no clinical trials have been performed so far with such UA formulations.

Structure-activity studies are extremely important as they indicate which features of the compound are crucial for its activity. Numerous modifications to the UA structure have been reported and screened for the antiproliferative activity. However, in majority of these reports, the molecular mechanism of action of the active derivatives has not been determined in detail. According to the published results, the enantiomeric structure of UA derivatives has no significant effect on their cancer inhibitory properties. Some of UA derivatives were designed to target specific enzymes which are crucial for cancer cells (such as mTOR, TDP1 or PARP). They might be used as sensitisers to currently used chemotherapeutics; however, their specificity should be thoroughly evaluated. Additionally, toxicological and pharmacokinetic studies for the most promising derivatives are important for their clinical development.

Acknowledgements We are grateful to Dr. Katarzyna Potrykus for critical reading of the manuscript and language correction. We express our apologies to researchers in the field of UA research that due to an oversight or space limitation could not be cited in this manuscript.

Funding Information This study was financially supported by the National Science Centre, Poland (project no. 2017/26/M/NZ7/00668).

\section{Compliance with Ethical Standards}

Conflict of Interest On behalf of all authors, the corresponding author states that there is no conflict of interest. 
Human and Animal Rights and Informed Consent This article does not contain any studies with human and animal subjects performed by any of the authors.

Open Access This article is distributed under the terms of the Creative Commons Attribution 4.0 International License (http:// creativecommons.org/licenses/by/4.0/), which permits unrestricted use, distribution, and reproduction in any medium, provided you give appropriate credit to the original author(s) and the source, provide a link to the Creative Commons license, and indicate if changes were made.

\section{References}

Papers of particular interest, published recently, have been highlighted as:

- Of importance

•- Of major importance

1. Bjerke JW, Elvebakk A, Dominguez E, Dahlback A. Seasonal trends in usnic acid concentrations of Arctic, alpine and Patagonian populations of the lichen Flavocetraria nivalis. Phytochemistry. 2005;66(3):337-44. https://doi.org/10.1016/j. phytochem.2004.12.007.

2. Ingolfsdottir K. Usnic acid. Phytochemistry. 2002;61(7):729-36.

3. Araujo AA, de Melo MG, Rabelo TK, Nunes PS, Santos SL, Serafini MR, et al. Review of the biological properties and toxicity of usnic acid. Nat Prod Res. 2015;29(23):2167-80. https://doi.org/ 10.1080/14786419.2015.1007455.

4. Luzina OA, Salakhutdinov NF. Biological activity of usnic acid and its derivatives: part 2. Effects on higher organisms. Molecular and physicochemical aspects. Russ J Bioorg Chem. 2016;42:249-68 The most recent comprehensive review of published data showing a wide range of bioactivities of $\mathrm{UA}$ and its derivatives.

5. Galanty A, Pasko P, Podolak I. Enantioselective activity of usnic acid: a comprehensive review and future perspectives. Phytochem Rev. 2019:18 This work organises knowledge on activities of UA enantiomers and highlighths its incompleteness.

6. Abo-Khatwa AN, al-Robai AA, al-Jawhari DA. Lichen acids as uncouplers of oxidative phosphorylation of mouse-liver mitochondria. Nat Toxins. 1996;4(2):96-102.

7. Pramyothin P, Janthasoot W, Pongnimitprasert N, Phrukudom S, Ruangrungsi N. Hepatotoxic effect of (+)usnic acid from Usnea siamensis Wainio in rats, isolated rat hepatocytes and isolated rat liver mitochondria. J Ethnopharmacol. 2004;90(2-3):381-7. https:// doi.org/10.1016/j.jep.2003.10.019.

8. Guo L, Shi Q, Fang JL, Mei N, Ali AA, Lewis SM, et al. Review of usnic acid and Usnea barbata toxicity. J Environ Sci Health $\mathrm{C}$ Environ Carcinog Ecotoxicol Rev. 2008;26(4):317-38. https://doi. org/10.1080/10590500802533392.

9. Sanchez W, Maple JT, Burgart LJ, Kamath PS. Severe hepatotoxicity associated with use of a dietary supplement containing usnic acid. Mayo Clin Proc. 2006;81(4):541-4. https://doi.org/10.4065/ 81.4.541.

10. Neff GW, Reddy KR, Durazo FA, Meyer D, Marrero R, Kaplowitz N. Severe hepatotoxicity associated with the use of weight loss diet supplements containing ma huang or usnic acid. J Hepatol. 2004;41(6):1062-4. https://doi.org/10.1016/j.jhep.2004.06.028.

11. Han D, Matsumaru K, Rettori D, Kaplowitz N. Usnic acid-induced necrosis of cultured mouse hepatocytes: inhibition of mitochondrial function and oxidative stress. Biochem Pharmacol. 2004;67(3): 439-51. https://doi.org/10.1016/j.bcp.2003.09.032.
12. da Silva Santos NP, Nascimento SC, Wanderley MS, Pontes-Filho NT, da Silva JF, de Castro CM, et al. Nanoencapsulation of usnic acid: an attempt to improve antitumour activity and reduce hepatotoxicity. Eur J Pharm Biopharm. 2006;64(2):154-60. https://doi. org/10.1016/j.ejpb.2006.05.018.

13. Sahu SC, Amankwa-Sakyi M, O’Donnell MW Jr, Sprando RL. Effects of usnic acid exposure on human hepatoblastoma HepG2 cells in culture. J Appl Toxicol. 2012;32(9):722-30. https://doi.org/ 10.1002/jat.1721.

14. Bessadottir M, Egilsson M, Einarsdottir E, Magnusdottir IH, Ogmundsdottir MH, Omarsdottir S, et al. Proton-shuttling lichen compound usnic acid affects mitochondrial and lysosomal function in cancer cells. PLoS One. 2012;7(12):e51296. https://doi.org/10. 1371/journal.pone.0051296.

15. Einarsdottir E, Groeneweg J, Bjornsdottir GG, Harethardottir G, Omarsdottir S, Ingolfsdottir K, et al. Cellular mechanisms of the anticancer effects of the lichen compound usnic acid. Planta Med. 2010;76(10):969-74. https://doi.org/10.1055/s-0029-1240851.

16. Joseph A, Lee T, Moland CL, Branham WS, Fuscoe JC, Leakey JE, et al. Effect of (+)-usnic acid on mitochondrial functions as measured by mitochondria-specific oligonucleotide microarray in liver of B6C3F1 mice. Mitochondrion. 2009;9(2):149-58. https://doi. org/10.1016/j.mito.2009.02.002.

17. Antonenko YN, Khailova LS, Rokitskaya TI, Nosikova ES, Nazarov PA, Luzina OA, et al. Mechanism of action of an old antibiotic revisited: role of calcium ions in protonophoric activity of usnic acid. Biochim Biophys Acta Bioenerg. 2019;1860(4):310 6. https://doi.org/10.1016/j.bbabio.2019.01.005.

18. Chen S, Dobrovolsky VN, Liu F, Wu Y, Zhang Z, Mei N, et al. The role of autophagy in usnic acid-induced toxicity in hepatic cells. Toxicol Sci. 2014;142(1):33-44. https://doi.org/10.1093/toxsci/ kfu154.

19. Chen S, Zhang Z, Wu Y, Shi Q, Yan H, Mei N, et al. Endoplasmic reticulum stress and store-operated calcium entry contribute to usnic acid-induced toxicity in hepatic cells. Toxicol Sci. 2015;146(1):116-26. https://doi.org/10.1093/toxsci/kfv075.

20. Bezivin C, Tomasi S, Rouaud I, Delcros JG, Boustie J. Cytotoxic activity of compounds from the lichen: Cladonia convoluta. Planta Med. 2004;70(9):874-7. https://doi.org/10.1055/s-2004-827240.

21. Nguyen TT, Yoon S, Yang Y, Lee HB, Oh S, Jeong MH, et al. Lichen secondary metabolites in Flavocetraria cucullata exhibit anti-cancer effects on human cancer cells through the induction of apoptosis and suppression of tumorigenic potentials. PLoS One. 2014;9(10):e111575. https://doi.org/10.1371/journal.pone. 0111575.

22. Backorova M, Jendzelovsky R, Kello M, Backor M, Mikes J, Fedorocko P. Lichen secondary metabolites are responsible for induction of apoptosis in HT-29 and A2780 human cancer cell lines. Toxicol in Vitro. 2012;26(3):462-8. https://doi.org/10.1016/j.tiv. 2012.01.017.

23.• Ebrahim HY, Ak1 MR, Elsayed HE, Hill RA, El Sayed KA. Usnic acid benzylidene analogues as potent mechanistic target of rapamycin inhibitors for the control of breast malignancies. J Nat Prod. 2017;80(4):932-52. https://doi.org/10.1021/acs.jnatprod. 6b00917 This work shows that UA inhbits mTOR pathway, rationally designs $\mathrm{UA}$ derivatives inhibiting this kinase as well as breast cancer cell proliferation and metastatic potential with higher than UA potency and validates their potential in vivo.

24. Song Y, Dai F, Zhai D, Dong Y, Zhang J, Lu B, et al. Usnic acid inhibits breast tumor angiogenesis and growth by suppressing VEGFR2-mediated AKT and ERK1/2 signaling pathways. Angiogenesis. 2012;15(3):421-32. https://doi.org/10.1007/ s10456-012-9270-4.

25. Kupchan SM, Kopperman HL. 1-usnic acid: tumor inhibitor isolated from lichens. Experientia. 1975;31(6):625. https://doi.org/10.1007/ bf01944592. 
26. Takai M, Uehara Y, Beisler JA. Usnic acid derivatives as potential antineoplastic agents. J Med Chem. 1979;22(11):1380-4. https:// doi.org/10.1021/jm00197a019.

27. Kristmundsdottir T, Aradottir HA, Ingolfsdottir K, Ogmundsdottir HM. Solubilization of the lichen metabolite (+)-usnic acid for testing in tissue culture. J Pharm Pharmacol. 2002;54(11):1447-52. https://doi.org/10.1211/002235702225.

28. Nikolic V, Stanković M, Nikolić L, Nikolić GS, Ilic-Stojanovic SS, Popsavin M, et al. Inclusion complexes with cyclodextrin and usnic acid. J Incl Phenom Macrocycl Chem. 2013;76:173-82.

29. Lira MCB, Ferraz MS, Silva DGVC, Cortes MEM, Teixeira KIR, Caetano NP, et al. Inclusion complex of usnic acid with $\beta$-cyclodextrin: characterization and nanoencapsulation into liposomes. $\mathrm{J}$ Incl Phenom Macrocycl Chem. 2009;64:215-24.

30.• Yang Y, Bae WK, Lee JY, Choi YJ, Lee KH, Park MS, et al. Potassium usnate, a water-soluble usnic acid salt, shows enhanced bioavailability and inhibits invasion and metastasis in colorectal cancer. Sci Rep. 2018;8(1):16234. https://doi.org/10.1038/s41598018-34709-9 Comprehensive work showing that UA potasium salt reveals much better features than UA, both in vitro on a number of cancer cell lines, and in animal model of metastasis. Moreover, it is less hepatotoxic and more bioavailable than UA.

31. Ribeiro-Costa RM, Alves AJ, Santos NP, Nascimento SC, Goncalves EC, Silva NH, et al. In vitro and in vivo properties of usnic acid encapsulated into PLGA-microspheres. J Microencapsul. 2004;21(4):371-84. https://doi.org/10.1080/ 02652040410001673919

32. Santos NPS, Nascimento SC, Silva JF, Pereira ECG, Silva NH, Honda NK, et al. Usnic acid-loaded nanocapsules: an evaluation of cytotoxicity. J Drug Deliv Sci Tec. 2005;15:355-61.

33. Martinelli A, Bakry A, D'Ilario L, Francolini I, Piozzi A, Taresco V. Release behavior and antibiofilm activity of usnic acid-loaded carboxylated poly(L-lactide) microparticles. Eur J Pharm Biopharm. 2014;88(2):415-23. https://doi.org/10.1016/j.ejpb.2014.06.002.

34. Ferraz-Carvalho RS, Pereira MA, Linhares LA, Lira-Nogueira MC, Cavalcanti IM, Santos-Magalhaes NS, et al. Effects of the encapsulation of usnic acid into liposomes and interactions with antituberculous agents against multidrug-resistant tuberculosis clinical isolates. Mem Inst Oswaldo Cruz. 2016;111(5):330-4. https://doi.org/ 10.1590/0074-02760150454.

35. Grumezescu AM, Saviuc C, Chifiriuc MC, Hristu R, Mihaiescu $\mathrm{DE}$, Balaure $\mathrm{P}$, et al. Inhibitory activity of $\mathrm{Fe}(3) \mathrm{O}(4) /$ oleic acid/usnic acid-core/shell/extra-shell nanofluid on S. aureus biofilm development. IEEE Trans Nanobioscience. 2011;10(4):269-74. https://doi.org/10.1109/TNB.2011.2178263.

36. Taresco V, Francolini I, Padella F, Bellusci M, Boni A, Innocenti C, et al. Design and characterization of antimicrobial usnic acid loaded-core/shell magnetic nanoparticles. Mater Sci Eng C Mater Biol Appl. 2015;52:72-81. https://doi.org/10.1016/j.msec.2015.03.044.

37. Grumezescu V, Holban AM, Grumezescu AM, Socol G, Ficai A, Vasile BS, et al. Usnic acid-loaded biocompatible magnetic PLGAPVA microsphere thin films fabricated by MAPLE with increased resistance to staphylococcal colonization. Biofabrication. 2014;6(3):035002. https://doi.org/10.1088/1758-5082/6/3/035002.

38. Qu C, Zhang L, Du X, Zhang X, Zheng J, Zhao Y, et al. Preparation and evaluation of wet-milled usnic acid nanocrystal suspension for better bioaffinity. Drug Dev Ind Pharm. 2018;44(5):707-12. https:// doi.org/10.1080/03639045.2017.1409756.

39. Luzina OA, Salakhutdinov NF. Usnic acid and its derivatives for pharmaceutical use: a patent review (2000-2017). Expert Opin Ther Pat. 2018;28(6):477-91. https://doi.org/10.1080/13543776.2018. 1472239 Review of patents published in 2000-2017 on therapeutic activities of $\mathrm{UA}$ and its derivatives.

40.• Garg A, Garg S, Sahu NK, Rani S, Gupta U, Yadav AK. Heparin appended ADH-anionic polysaccharide nanoparticles for sitespecific delivery of usnic acid. Int J Pharm. 2019;557:238-53. https://doi.org/10.1016/j.ijpharm.2018.12.049 The work shows that UA-loaded heparin-modified gellan gum nanoparticles are superior than UA against lung cancer cells, characterised by sustained liberation of active compound and more favourable bio-distribution and safety in vivo.

41. Garg A, Sahu NK, Yadav AK. Usnic acid-loaded bioinspired heparin modified-cellulose acetate phthalate nanoparticle(s) as an efficient carrier for site-specific delivery in lung cancer cell. Int J Pharm Investig. 2018;8:53-62

42. Mukerjee A, Pandey H, Tripathi AK, Singh SK. Development, characterization and evaluation of cinnamon oil and usnic acid blended nanoemulsion to attenuate skin carcinogenicity in swiss albino mice. Biocatal Agric Biotechnol. 2019;20.

43. Garg S, Garg A, Sahu NK, Yadav AK. Synthesis and characterization of nanodiamond-anticancer drug conjugates for tumor targeting. Diam Relat Mater. 2019;94:172-85.

44. Yu X, Guo Q, Su G, Yang A, Hu Z, Qu C, et al. Usnic acid derivatives with cytotoxic and antifungal activities from the lichen Usnea longissima. J Nat Prod. 2016;79(5):1373-80. https://doi.org/10. 1021/acs.jnatprod.6b00109.

45. Bazin MA, Le Lamer AC, Delcros JG, Rouaud I, Uriac P, Boustie J, et al. Synthesis and cytotoxic activities of usnic acid derivatives. Bioorg Med Chem. 2008;16(14):6860-6. https://doi.org/10.1016/j. bmc.2008.05.069.

46. Zakharenko A, Luzina O, Koval O, Nilov D, Gushchina I, Dyrkheeva N, et al. Tyrosyl-DNA phosphodiesterase 1 inhibitors: usnic acid enamines enhance the cytotoxic effect of camptothecin. J Nat Prod. 2016;79(11):2961-7. https://doi.org/10.1021/acs. jnatprod.6b00979.

47. Zakharova O, Luzina O, Zakharenko A, Sokolov D, Filimonov A, Dyrkheeva N, et al. Synthesis and evaluation of aryliden- and hetarylidenfuranone derivatives of usnic acid as highly potent Tdp1 inhibitors. Bioorg Med Chem. 2018;26(15):4470-80. https://doi.org/10.1016/j.bmc.2018.07.039.

48.• Zakharenko A, Luzina O, Koval O, Nilov D, Gushchina I, Dyrkheeva N, et al. Novel tyrosyl-DNA phosphodiesterase 1 inhibitors enhance the therapeutic impact of topotecan on in vivo tumor models. Eur J Med Chem. 2019;161:581-93. https://doi. org/10.1016/j.ejmech.2018.10.055 This work shows UA derivatives, which were designed to inhibit TDP1 enzyme, and are non-toxic to cancer cells but sensitise them to topotecan. Their activity is validated in vivo.

49. Zakharenko A, Sokolov D, Luzina O, Sukhanova M, Khodyreva S, Zakharova $\mathrm{O}$, et al. Influence of usnic acid and its derivatives on the activity of mammalian poly(ADP-ribose)polymerase 1 and DNA polymerase $\beta$. Med Chem. 2012;8:883-93.

50. Venkata Mallavadhani U, Vanga NR, Balabhaskara Rao K, Jain N. Synthesis and antiproliferative activity of novel (+)- usnic acid analogues. J Asian Nat Prod Res. 2019:1-16. https://doi.org/10.1080/ 10286020.2019 .1603220$.

51. Pyrczak-Felczykowska A, Narlawar R, Pawlik A, GuzowKrzeminska B, Artymiuk D, Hac A, et al. Synthesis of usnic acid derivatives and evaluation of their antiproliferative activity against cancer cells. J Nat Prod. 2019;82(7):1768-78. https://doi.org/10. 1021/acs.jnatprod.8b00980.

52. Dyrkheeva N, Luzina O, Filimonov A, Zakharova O, Ilina E, Zakharenko A, et al. Inhibitory effect of new semisynthetic usnic acid derivatives on human tyrosyl-DNA phosphodiesterase 1 . Planta Med. 2019;85(2):103-11. https://doi.org/10.1055/a-06817069.

53. Wang S, Zang J, Huang M, Guan L, Xing K, Zhang J, et al. Discovery of novel (+)-usnic acid derivatives as potential antileukemia agents with pan-Pim kinases inhibitory activity. Bioorg Chem. 2019;89:102971. https://doi.org/10.1016/j.bioorg.2019. 102971. 
54. Nguyen HGT, Nguyen NV, Vo VA, Chun W, Kamounah FS, Vang $\mathrm{O}$, et al. Synthesis, structure elucidation and cytotoxicity of (+)usnic acid derivatives on U87MG glioblastoma cells. Nat Prod Chem Res. 2016;4:1-6.

55. Nguyen VK, Sichaem J, Nguyen HH, Nguyen XH, Huynh TT, Nguyen TP, et al. Synthesis and cytotoxic evaluation of usnic acid benzylidene derivatives as potential anticancer agents. Nat Prod Res. 2019:1-10. https://doi.org/10.1080/14786419.2019.1639176.

Publisher's Note Springer Nature remains neutral with regard to jurisdictional claims in published maps and institutional affiliations. 